\title{
ON THE TOLERATION OF ANAEROBIC CONDITIONS BY CALIGUS DIAPHANUS NORDMANN
}

\author{
By S. KRISHNASWAMY \\ Department of Zoology, University of Southampton *
}

Many free-living and parasitic invertebrates have been known to tolerate low oxygen tensions and anaerobic conditions. Von Brand (1946) who reviewed the extensive literature on anaerobiosis in invertebrates listed species of Cyclops which under experimental conditions could tolerate 2-I8 h of anaerobiosis. Apart from this, few experimental studies have been made on anaerobiosis in copepods, especially the parasitic species. Availability of a number of live Caligus diaphanus at Plymouth made it possible to make a few preliminary observations on the behaviour of this copepod parasite under anaerobic conditions.

\section{MATERIAL AND METHODS}

Gurnards (Trigla sp.) examined at Plymouth, were found to be infected by Caligus diaphanus Nordmann, the parasite being usually found on the inner side of the operculum. Although over a hundred gurnards were examined it was possible to obtain only ten parasites.

Experimental anaerobic conditions were produced by bubbling oxygenfree nitrogen from a cylinder into sea water. The nitrogen was first passed through a wash-bottle containing alkaline-pyrogallol to remove any traces of oxygen. Estimations of dissolved oxygen using Winkler's method usually gave a value which was equivalent only to that found dissolved in the reagents. Bubbling nitrogen for $40 \mathrm{~min}$ usually produced very low oxygen tensions. Four parasites were transferred to a small glass-stoppered bottle $(30 \mathrm{ml}$. capacity) and flushed with oxygen-free sea water under liquid paraffin. The glass stopper was inserted and smeared with stop-cock grease to prevent air leaking into the bottle. The bottles were immersed in a trough of water kept at room temperature $\left(18^{\circ} \mathrm{C}\right)$. A similar number of animals in identical bottles with fresh sea water served as control.

C. diaphanus when left in fresh sea water usually attaches itself to the sides or to the bottom of the container. The urosome of the animal is usually slightly tilted at an angle and shows periodic movement. The thigmotactic behaviour of the parasite in remaining attached to the surface of the container was used as a measure of behaviour under low oxygen tensions. Caligus is

* Present address: Zoological Research Laboratory, Madras University, Madras, India. 
also slightly transparent and the anal peristalsis could be easily observed in live animals. This was used as an indication of the recovery of these animals after transferring to fresh sea water from anaerobic conditions.

When exposed to anaerobic conditions, the animals usually become detached and lie inactive at the bottom of the container although anal peristalsis continues. Under anaerobic conditions the time taken by the animal to become detached varied from Io min to $4 \mathrm{~h}$. The results are tabulated in Table I.

TABLE 1. TOLERATION OF ANAEROBIC CONDITIONS BY CALIGUS DIAPHANUS

\begin{tabular}{|c|c|c|c|}
\hline \multirow{2}{*}{$\begin{array}{l}\text { Time of } \\
\text { exposure of } \\
\text { anaerobiosis }\end{array}$} & \multicolumn{3}{|c|}{ No. of animals } \\
\hline & $\begin{array}{l}\text { Active and } \\
\text { attached }\end{array}$ & Moribund & Dead \\
\hline Io $\mathrm{min}$ & 4 & - & - \\
\hline ro $\min$ & 4 & - & \\
\hline $20 \mathrm{~min}$ & 4 & - & - \\
\hline $30 \mathrm{~min}$ & 2 & - & - \\
\hline $30 \mathrm{~min}$ & 4 & - & - \\
\hline $45 \mathrm{~min}$ & - & 4 & - \\
\hline I h & - & 2 & 2 \\
\hline I $\mathrm{h}$ & 4 & - & - \\
\hline $\mathrm{I}_{\frac{1}{2}} \mathrm{~h}$ & 4 & - & - \\
\hline $2 \mathrm{~h}$ & 4 & - & - \\
\hline $2 \mathrm{~h}$ & 2 & - & 2 \\
\hline $3 \mathrm{~h}$ & 2 & - & I \\
\hline $3 \mathrm{~h}$ & - & 2 & 2 \\
\hline $4 \mathrm{~h}$ & I & 3 & - \\
\hline $4 \mathrm{~h}$ & I & 3 & - \\
\hline $8 \mathrm{~h}$ & - & - & 4 \\
\hline $9 \mathrm{~h}$ & - & - & 4 \\
\hline
\end{tabular}

Note: Three types of reaction were used as arbitrary criteria in these experiments. (I) active and attached; (2) moribund, i.e. lying inert on the bottom but showing anal peristalsis. (3) dead, i.e. not reacting to mechanical stimuli. Four animals were used in each experiment; four animals in fresh sea water served as control.

TABLE 2. THE TIME TAKEN FOR RECOVERY OF CALIGUS DIAPHANUS AFTER A PERIOD OF ANAEROBIOSIS

$\begin{array}{ccc}\text { No. of animals } & \begin{array}{c}\text { Duration of } \\ \text { anaerobiosis } \\ \text { (h) }\end{array} & \begin{array}{c}\text { Time taken fo } \\ \text { complete recove } \\ \text { (min) }\end{array} \\ \text { I } & 3 & 2 \\ \text { I } & 3 & 4 \\ 2^{\star} & 3 & 2 \\ 2 & 3 & 2 \\ 2 & 3 & 3 \\ \text { I } & 4 & \text { No recovery } \\ 2 & 4 & 15 \\ 2 & 4 & 15 \\ 2 & 4 & 10 \\ \text { I } & 8 & 20 \\ & 9 & 30\end{array}$

Note. In a few instances owing to shortage of material, the same animals had to be used in more than one experiment. (These experiments are shown with an asterisk.) The use of the same animals did not cause any variation. 
On transferring to fresh sea water over $60 \%$ of the parasites recovered. The time taken for complete recovery, i.e. for the animal which lies moribund to be attached again varied from 2 to $30 \mathrm{~min}$, depending on the time of exposure to anaerobic conditions (Table 2). The animals under anaerobic conditions for $3 \mathrm{~h}$ recovered in 2-3 min, while animals exposed to similar conditions for $4 \mathrm{~h}$ recovered in $4^{-15} \mathrm{~min}$. Prolonged exposure of 8 and $9 \mathrm{~h}$ duration (in two experiments) resulted in the animal recovering after a period of 20-30 min.

The results would tend to show that $C$. diaphanus is capable of enduring anaerobic conditions without apparent ill effects.

I wish to thank Prof. J. E. G. Raymont, Professor of Zoology, University of Southampton, for several valuable suggestions and the Director and Staff of the Marine Biological Laboratory, Plymouth, for all the facilities given while working there.

\section{REFERENCES}

BRAND, TH., von, 1946. Anaerobiosis in invertebrates. Biodynamica, Monogr. 4,

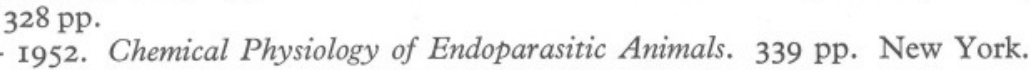

Scotт, T. \& Scott, A., I913. The British Parasitic Copepoda. 252 pp. London: Ray. Soc.

WiLsoN, C. B., 1905. North American parasitic Copepoda belonging to the Family Caligidae. Proc. U.S. nat. Mus., Vol. 28, pp. 479-672. 